d

D2 MSN-specific RNA-seq clustering:

Original

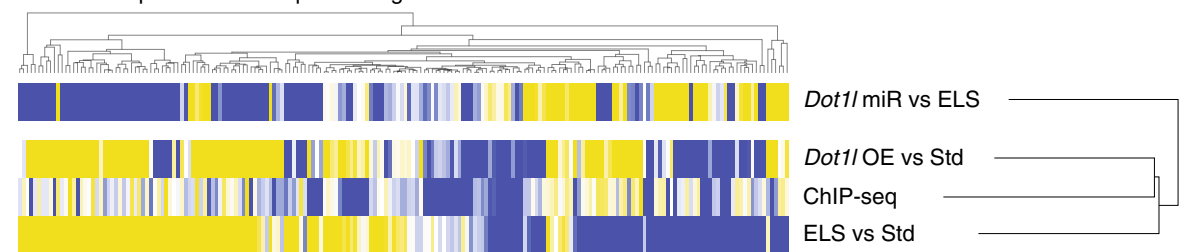

f

Corrected

d

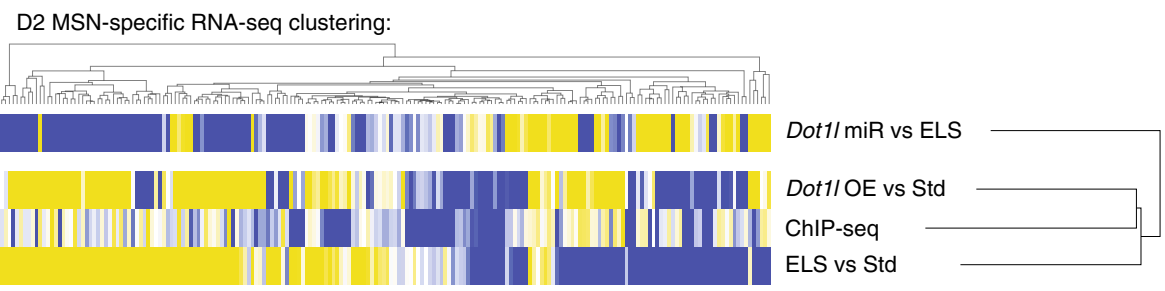

f
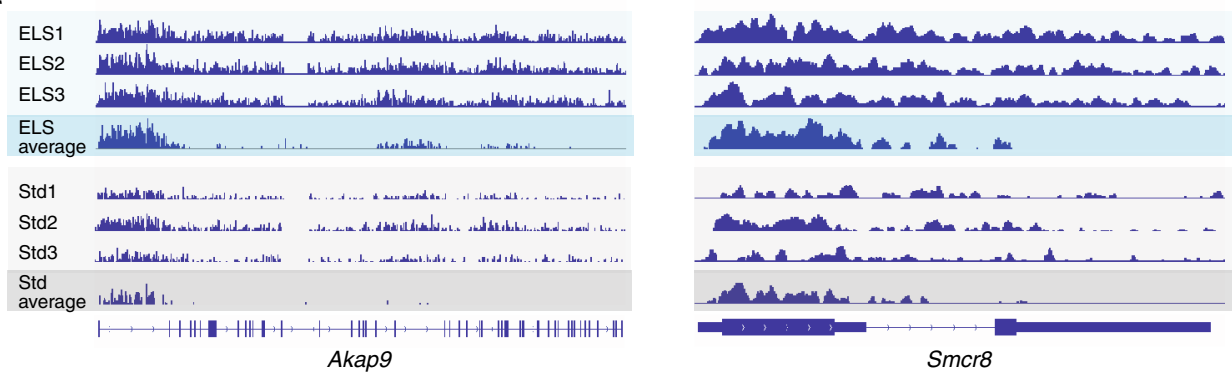

Fig. 5 | Original and Corrected.

Published online: 8 April 2021

https://doi.org/10.1038/s41593-021-00848-y

(c) The Author(s), under exclusive licence to Springer Nature America, Inc. 2021

\title{
Author Correction: A comprehensive thalamocortical projection map at the mesoscopic level
}

Barbara J. Hunnicutt, Brian R. Long, Deniz Kusefoglu, Katrina J. Gertz, Haining Zhong and Tianyi Mao

Correction to: Nature Neuroscience https://doi.org/10.1038/nn.3780, published online 3 August 2014.

Legacy: The URL provided in the Methods section for the data repository where raw data and analyzed data were available is no longer active. These data are now publicly available at: https://doi.org/10.6083/M4MW2FGS.

Published online: 24 March 2021

https://doi.org/10.1038/s41593-021-00838-0

(c) The Author(s), under exclusive licence to Springer Nature America, Inc. 2021 